\title{
Clinical Evaluation of Xylazine-Butorphanol-Guaifenesin- Ketamine as Short-Term TIVA in Equines
}

\author{
Bhanu Partap Singh Thakur, Sandeep Kumar Sharma, Arvind Sharma, and Adarsh Kumar \\ Department of Surgery and Radiology, Dr. G. C. Negi College of Veterinary \& Animal Sciences, \\ CSK Himachal Pradesh Agriculture University, Palampur (HP) 176 062, India \\ Correspondence should be addressed to Sandeep Kumar Sharma, sandeepsharma956@gmail.com
}

Received 15 December 2010; Revised 15 February 2011; Accepted 7 March 2011

Academic Editor: William Ravis

Copyright (C) 2011 Bhanu Partap Singh Thakur et al. This is an open access article distributed under the Creative Commons Attribution License, which permits unrestricted use, distribution, and reproduction in any medium, provided the original work is properly cited.

\begin{abstract}
Xylazine (1.1 mg/kg), butorphanol (0.02 mg/kg), guaifenesin 5\% (20 mg/kg), and ketamine $(2.2 \mathrm{mg} / \mathrm{kg})$ combinations were able to induce short-term surgical anaesthesia for $23.33 \pm 2.57 \mathrm{~min}$ in Spiti ponies with excellent to good muscle relaxation and analgesia. Urination and neighing was a constant feature during recovery period. Biphasic P wave, biphasic T wave, and depressed PR segment were common electrocardiographic findings. Biochemical attributes were within physiological limits except a significant increase in ALT values during anaesthesia. The values returned to normal during recovery ruling out any renal or hepatic toxicity. Occasionally, negative $\mathrm{T}$ wave, notched $\mathrm{P}$ wave, and sinus block were noticed. It is recommended that the anaesthetic combinations xylazinebutorphanol-guaifenesin-ketamine can be safely used for short-term total intravenous anaesthesia (TIVA) in equines under field conditions.
\end{abstract}

\section{Introduction}

Equines are routinely presented to veterinary hospitals for variety of surgical interventions, and their temperament often precludes the use of local analgesia without heavy sedation (Hall and Clarke [1]). The use of total intravenous anaesthesia (TIVA) helps in reducing a variety of preanaesthetic, anaesthetic, and postanaesthetic problems such as arrhythmias, hypotension, respiratory or ventilatory insufficiency, motor excitement, and anxiety or postanaesthetic myopathy (Garcia et al. [2]). High-altitude equines are hardy animals which thrive under cold arid conditions, where extreme cold temperature and low atmospheric oxygen are considerable factors. Therefore, the aim of the present study was to evaluate a safe short-term TIVA protocol in Spiti ponies using xylazine-butorphanol-guaifenesin-ketamine to manage a large number of surgical interventions and medical procedures.

\section{Material and Methods}

The present study was carried out in 6 clinically healthy adult male Spiti ponies, $4.27 \pm 1.63$ years old and weighing $181.66 \pm 32.26 \mathrm{~kg}$, presented for castration. Animals were fasted overnight and water was withheld for 6-8 hours. Xylazine (Xylazil-100 injection $(100 \mathrm{mg} / \mathrm{mL})$, ILIUM, Troy Laboratories, Australia.) (1.1 mg/Kg) was administered intravenously and subsequently at head-down position; the animals received butorphanol (Butrum $(2 \mathrm{mg} / \mathrm{mL}$ ) Aristo Pharmaceuticals Pvt. Ltd; Mumbai.) at the dose rate of $0.02 \mathrm{mg} / \mathrm{Kg}$ and $5 \%$ guaifenesin (Guaifenesin IP Prudential Pharmaceuticals Ltd; Andhra Pradesh, India.) $(20 \mathrm{mg} / \mathrm{Kg})$, both intravenously. As soon as the signs of ataxia developed, induction of surgical anaesthesia was achieved by intravenous administration of ketamine hydrochloride (Ketamil-100 injection (100 mg/mL), ILIUM, Troy Laboratories, Australia.) at the rate of $2.2 \mathrm{mg} / \mathrm{Kg}$. During induction, the horses were properly restrained to prevent forward fall. After induction, the horses were left undisturbed for one minute, and neck was extended to maintain a patent airway. The maintenance of anaesthesia, if required (when flinching of limbs or return of swallowing reflex was observed), was achieved by ketamine hydrochloride $1.0 \mathrm{mg} / \mathrm{kg}$, intravenously, until movements or swallowing ceased.

The anaesthetic parameters recorded during each clinical trial were time for sedation/ataxia, time for induction, duration of surgical anaesthesia, and recovery time. The depth 
TABLE 1: Score card for quality of muscle relaxation.

\begin{tabular}{|c|c|c|}
\hline \multicolumn{3}{|r|}{ Quality of muscle relaxation } \\
\hline Score & Quality & Character \\
\hline 4 & Excellent & Complete relaxation \\
\hline 3 & Good & $\begin{array}{l}\text { Adequate muscle relaxation for surgical } \\
\text { procedure }\end{array}$ \\
\hline 2 & Moderate & $\begin{array}{l}\text { Partial relaxation of head, neck, and limb } \\
\text { muscles }\end{array}$ \\
\hline 1 & Poor & Rigidity in muscles of neck, head, and limbs \\
\hline
\end{tabular}

TABLE 2: Score card for quality of analgesia.

\begin{tabular}{lcl}
\hline Score & Quality & Character \\
\hline 0 & Excellent & No response \\
1 & Good & Response to stimuli, nystagmus created \\
2 & Moderate & $\begin{array}{l}\text { Purposeful movement of limbs, head, or } \\
\text { neck produced }\end{array}$ \\
3 & Poor & Horse moved into sternal position or stood \\
\hline
\end{tabular}

TABLE 3: Score card for quality of recovery.

\begin{tabular}{lcl}
\hline Score & Quality & $\begin{array}{l}\text { Quality of recovery } \\
\text { Character }\end{array}$ \\
\hline 1 & Excellent & $\begin{array}{l}\text { Horse capable of standing at first attempt } \\
\text { Horse remained calm and needed two } \\
\text { attempts to stand }\end{array}$ \\
3 & Very good & $\begin{array}{l}\text { Horse remained calm but needed more than } \\
\text { two attempts to stand } \\
\text { Excitement during recovery with danger of } \\
\text { injury and needed more than one attempt to } \\
\text { stand } \\
\text { Severe excitement during recovery with } \\
\text { injury }\end{array}$ \\
\hline
\end{tabular}

of anaesthesia (light or deep) was analyzed by recording different reflexes (palpebral, corneal, photopupillary, and swallowing) and extent of muscle relaxation (relaxation of neck, jaws, tail, and anal sphincter, Table 1).

Analgesia (using pin prick method to test the response to noxious stimuli on the coronary band of the front and hind limbs, the shoulders, and the gaskin) was interpreted as a response, and score was given ranging from 0 to 3 (Nanda, [3]) as per Table 2.

A score, ranging from 1 to 5 as per the method of Ringer et al. [4], was used for the assessment of quality of recovery from anaesthesia (Table 3 ).

The clinical parameters like heart rate, respiratory rate, and rectal temperature were recorded. Respiration rate was recorded by observing costoabdominal movements manually and by vital signs monitor (Multi Para Monitor-Execello BPL, Bangalore, India), heart rate by auscultation and vital sign monitor, and gingival perfusion time and $\mathrm{SpO}_{2}$ by tongue transducer attached to vital sign monitor. Electrocardiograms (ECGs) were also recorded using bipolar base apex lead system. The calibrations made were conduction of $1 \mathrm{mV}=1 \mathrm{~cm}$ and paper speed of $25 \mathrm{~mm} / \mathrm{sec}$. The electrocardiograms were analyzed for various conduction abnormalities if any. All the observations were made before induction (BI), after induction (AI), during anaesthesia (DAn-15 min after induction), and after recovery (AR).

The venous blood from jugular vein was collected at different time intervals as mentioned above for monitoring of haemoglobin, packed cell volume, and total leukocyte count using blood cell counter (BC-2800 Vet Auto Hematology Analyzer-Mindray, China) and various biochemical parameters, namely, blood glucose, aspartate aminotransferase, alanine aminotransferase, alkaline phosphatase, chloride, total proteins, blood urea nitrogen, and creatinine using commercially available kits on computerized semiautomatic blood analyzer (RA-50 Chemistry Analyzer, Bayer Diagnostics, Baroda, Gujarat, India). Estimation of sodium and potassium was done by flame photometry. Data was expressed as Mean \pm SEM, and statistical analysis was carried out by one-way ANOVA with post hoc Dunnett's test performed using GraphPad InStat. $P$ value was considered significant when $P<.05$ and highly significant when $P<.01$.

\section{Results and Discussion}

The dosages adapted in the present study have been well documented in the literature (Kerr et al. [5]; Muir et al. [6]; Butera et al. [7]; Kaka et al. [8]). Xylazine and ketamine combination is commonly used for induction and maintenance of anaesthesia in horses [6], whereas the addition of guaifenesin helps to achieve desirable effects (analgesia, unconsciousness, and muscle relaxation) associated with general anaesthesia as menthioned by Muir et al. [9]. Butorphanol, an agonist-antagonist opioid, was used in the present study for profound sedation and surgical analgesia because the use of only agonist opioid induces different excitement states during anaesthesia in horses [2].

The onset of sedation (lowering of head) was observed in $2.5 \pm 0.85 \mathrm{~min}$, which is because of significant muscle relaxation by xylazine (Hubbell et al. [10]). The sedative and analgesic property of xylazine is due to CNS depression mediated by stimulation of alpha 2 receptors (Hsu [11]). The animals were ataxic at $1.0 \pm 0 \mathrm{~min}$ following butorphanol and guaifenesin administration. The induction of surgical anaesthesia was achieved in $2.66 \pm 0.66 \mathrm{~min}$ following intravenous ketamine. During recovery, limb/head movement and sternal recumbency was attained in 18.0 $\pm 3.21 \mathrm{~min}$ and $28.56 \pm 2.23 \mathrm{~min}$, respectively. Similar observations have been reported by McCarty et al. [12] and Baetge et al. [13], as they recorded the sternal recumbency in $30.0 \mathrm{~min}$ and in $15.0 \pm 6.0 \mathrm{~min}$, respectively. Standing ataxia and normal gait were seen at $32.16 \pm 3.20 \mathrm{~min}$ and $48.83 \pm 3.99 \mathrm{~min}$, respectively, after induction of anaesthesia with ketamine. Ketamine hydrochloride exerts its effect on CNS during induction and produces functional and electrophysiological dissociation of thalamocortical areas from limbic and other subcortical structures in the brain; as a result, consciousness is lost (Staffieri and Driessen [14]). Maintenance of anaesthesia was required in two horses by topping up with ketamine at the dose rate of $1.0 \mathrm{mg} / \mathrm{kg}$, 
TABLe 4: Clinical and haematological effects following Xylazine-butorphanol-Guaifenesin-Ketamine anaesthesia in Spiti ponies $(n=6)$.

\begin{tabular}{lcccc}
\hline Parameters (unit) & Before induction $(\mathrm{BI})$ & After induction $(\mathrm{AI})$ & During anaesthesia $(\mathrm{DAn})$ & After recovery $(\mathrm{AR})$ \\
\hline Rectal temp $\left({ }^{\circ} \mathrm{F}\right)$ & $98.65 \pm 0.29$ & $98.88 \pm 0.41$ & $98.03 \pm 0.53$ & $98.13 \pm 0.42$ \\
Heart rate (per min) & $49.50 \pm 0.93$ & $43.00 \pm 3.44$ & $40.66 \pm 4.03$ & $42.00 \pm 2.63$ \\
Respiratory rate (per min) & $28.00 \pm 4.93$ & $16.33 \pm 1.48$ & $19.33 \pm 3.30$ & $26.17 \pm 3.06$ \\
$\mathrm{Hb}(\mathrm{g} / \mathrm{dL})$ & $10.03 \pm 0.43$ & $9.92 \pm 0.71$ & $9.60 \pm 0.36$ & $10.93 \pm 1.22$ \\
PCV (\%) & $26.43 \pm 1.17$ & $27.52 \pm 1.57$ & $25.45 \pm 1.04$ & $26.60 \pm 0.96$ \\
TLC (thous. $\left./ \mathrm{mm}^{3}\right)$ & $8.87 \pm 2.16$ & $8.17 \pm 1.87$ & $8.75 \pm 0.70$ & $8.29 \pm 0.75$ \\
\hline
\end{tabular}

IV (total dose approximating to $140 \mathrm{mg}$ ). In the present study, 5 of the Spiti ponies had excellent recoveries with only one pony taking two attempts to stand with moderate ataxia. In general, horses induced anaesthesia with xylazine and ketamine experience smooth recoveries characterized by a roll to sternal recumbency and a single attempt to stand (Aubin and Mama [15]). Urination and neighing was a constant feature during recovery period except in one horse. The lacrimation was observed in three horses probably indicating light plane of anaesthesia. The palpebral and corneal reflexes were suppressed after induction and during anaesthesia. Eye evaluation, which is usually used to judge the depth of anaesthesia, is of limited value following administration of ketamine because of the responses like voluntary blinking, nystagmus (Bertone and Horspool [16]), and lacrimation. This effect may be attributed to ketamine which is often referred to as cateleptoid anaesthesia, which differs markedly from the classical signs of anaesthesia. Ketamine appears to alter the reactivity of the CNS to various sensory impulses without blocking the sensory inputs at spinal or brain stem levels. The input may reach the cortical receiving areas but fails to be perceived because of the depression or disorganization of the associated areas during the period of anaesthesia (Spark et al. [17]; Wright [18]). The swallowing reflex was depressed in all the operated horses.

The TIVA combination used in the present study produced excellent to good muscle relaxation during anaesthesia in all the animals as evidenced by relaxation of jaw, neck, tail, and anal sphincter. The muscle relaxation is largely attributed to guaifenesin which acts centrally by depressing or blocking nerve impulse transmission at subcortical areas of brain, brainstem, and spinal cord (Cullen [19]). The loss of anal tone was noticed initially after induction and was last to return to normal during recovery. There was complete to moderate analgesia during anaesthesia in all the animals which remained for $23.33 \pm 2.57 \mathrm{~min}$ following the induction of anaesthesia as has also been demonstrated by Geiser and Henton [20], where analgesia in horses remained for 30-35 min which is due to reduced electrical activity of brain produced by a combination of xylazine and ketamine (Purohit et al. [21]).

The rectal temperature remained unaffected during the period of study, whereas nonsignificant decreases in heart rate and respiration rate were observed after induction and during anaesthesia (Table 4). However, the changes recorded were within normal range. A similar trend was observed following continuous intravenous triple drip of xylazineketamine-guaifenesin [3]. The decrease in respiration rate can be related to direct depression of respiratory centres by xylazine (Rings and Muir [22]). Butorphanol is also a potential respiratory depressant drug although no serious effect was observed by Robertson et al. [23] when it was injected in healthy horses. The decrease in the heart rate is attributed to xylazine-induced vagal stimulation. All the hematological parameters, namely, hemoglobin, PCV, and TLC remained within the normal range in the present study (Table 4). A significant decrease in PCV and TLC and a nonsignificant decrease in $\mathrm{Hb}$ have been reported following continuous intravenous triple drip of xylazine-ketamineguaifenesin in spiti ponies [3]. The mean $\mathrm{SpO}_{2}$ value in equines remained within $82.18 \pm 5.33$ and $87 \pm 2.94 \%$ during surgical plan of anaesthesia. If at all we consider it as hypoxemia (as the base values of $\mathrm{SpO} 2$ could not be obtained in the present study), it could be due to some drop in oxygenation probably happened as is commonly seen in horses under general anaesthesia because the assumption of lateral recumbency is associated with the development of ventilation-perfusion mismatches and the shunting of blood through the lungs resulting in less than optimal oxygenation (Hubbel [24]). Also it could be due to the low atmospheric oxygen since the anaesthetic trials were conducted at high altitude (1500 msl).

Biphasic $\mathrm{T}$ wave was a constant observation in all the horses before administration of any drug (Figure 1). In one horse, PR segment was depressed, whereas ST segment elevation was noticed in another two horses at base. After induction of anaesthesia, biphasic $\mathrm{P}$ wave, biphasic $\mathrm{T}$ wave, shortening of QRS segment, and slight elevation of ST segment were recorded in all the animals. All the ECG changes recorded in this study represent normal impulse conduction and hence are of no clinical relevance. Occasional conduction abnormalities seen during anaesthesia in different Spiti ponies are likely a consequence of xylazine used in the present study.

All the preinduction plasma samples of Spiti ponies evaluated for various biochemical parameters were within normal range (Table 5). There was a highly significant $(P<$ .01 ) increase in the plasma ALT values during anaesthesia. The increase in ALT values could probably be due to alteration in cell membrane permeability which may permit these enzymes to leak from cells with intact membrane (Tiwari et al. [25]). Also a significant $(P<.05)$ increase 


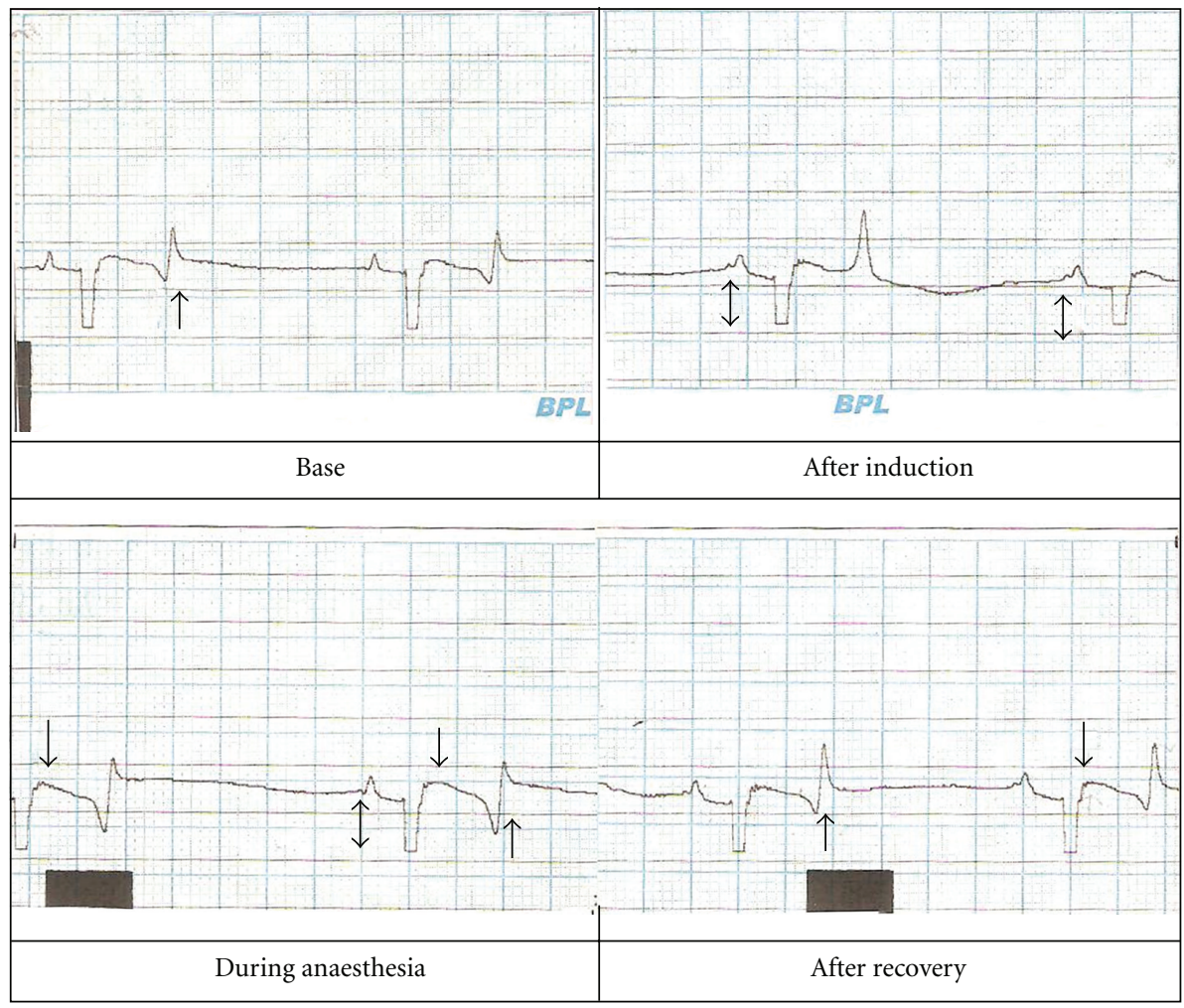

Paper speed $25 \mathrm{~mm} / \mathrm{s} ; 1 \mathrm{mV}=1 \mathrm{~cm}$;

$\begin{array}{ll}\uparrow \text { Biphasic T wave } & \downarrow \text { ST segment elevation } \\ \uparrow \text { Biphasic } \mathrm{P} \text { wave } & \end{array}$

FIGURE 1: Electrocardiogram of a Spiti pony following xylazine-butorphanol-guaifenesin-ketamine anesthesia showing different wave changes.

TABLE 5: Biochemical effects following Xylazine-butorphanol-Guaifenesin-Ketamine anaesthesia in Spiti ponies $(n=6)$.

\begin{tabular}{lcccc}
\hline Parameters (unit) & Before induction $(\mathrm{BI})$ & After induction $(\mathrm{AI})$ & During anaesthesia $(\mathrm{DAn})$ & After recovery $(\mathrm{AR})$ \\
\hline Sodium $(\mathrm{mEq} / \mathrm{L})$ & $128.05 \pm 11.70$ & $122.80 \pm 11.16$ & $113.93 \pm 5.32$ & $109.80 \pm 5.72$ \\
Potassium $(\mathrm{mEq} / \mathrm{L})$ & $4.17 \pm 0.39$ & $3.93 \pm 0.29$ & $8.12 \pm 0.69$ & $3.29 \pm 0.31$ \\
Chloride $(\mathrm{mEq} / \mathrm{L})$ & $79.15 \pm 12.44$ & $81.30 \pm 7.50$ & $125.66 \pm 13.66$ & $77.41 \pm 5.43$ \\
Glucose $(\mathrm{mg} / \mathrm{dL})$ & $75.50 \pm 11.03$ & $119.17 \pm 14.77$ & $10.83 \pm 0.61$ & $120.83 \pm 13.42$ \\
Total proteins (g/dL) & $8.60 \pm 0.49$ & $10.60 \pm 0.49$ & $176.83 \pm 29.37$ & $10.36 \pm 1.06$ \\
AST (U/L) & $241.00 \pm 29.24$ & $200.33 \pm 25.39$ & $18.44^{* *} \pm 0.62$ & $169.16 \pm 29.78$ \\
ALT (U/L) & $13.60 \pm 0.63$ & $18.92^{* *} \pm 0.60$ & $111.17 \pm 2.48$ & $13.18 \pm 0.71$ \\
ALKP(U/L) & $123.00 \pm 4.12$ & $138.00^{*} \pm 3.54$ & $23.28 \pm 1.66$ & $118.50 \pm 3.56$ \\
BUN (mg/dL) & $25.70 \pm 2.97$ & $24.33 \pm 2.18$ & $0.78 \pm 0.06$ & $22.05 \pm 1.98$ \\
Creatinine (mg/dL) & $0.81 \pm 0.05$ & $0.74 \pm 0.05$ & & $0.84 \pm 0.14$ \\
\hline
\end{tabular}

${ }^{*} P<.05 ;{ }^{* *} P<.01$.

in plasma ALKP values was noticed immediately after the induction of anaesthesia. Since the range of ALKP values in horses is wide that a change in its value is of no clinical relevance. Although there was evidence of nonsignificant $(P>.05)$ hyperglycemia throughout the period of study following the induction of anaesthesia, the clinical relevance of such an increase in the glucose levels cannot be ruled out. The increase in plasma glucose level was probably due to an alpha2 adrenergic inhibition of insulin release by stimulation of alpha 2 receptors in the pancreatic $\beta$-cells (Angel and Langer [26]). Ketamine hydrochloride generally increases norepinephrine blood levels and turnover. Since norepinephrine affects gluconeogenesis and glycogenolysis and also decreases insulin production, enhanced hyperglycemic effects after ketamine administration are obvious. A significant hyperglycemia following general anesthesia 
has been reported in horses (Young et al. [27]; Singh et al. [28]). However, since these changes were statistically nonsignificant; therefore, they reflect no effect on renal blood flow in the present study. The remaining biochemical parameters remained within normal range throughout the period of study reflecting no alterations in body electrolyte balance as well as absence of any hepatic or renal toxicity in the present study.

\section{Conclusion}

It was concluded that xylazine $(1.1 \mathrm{mg} / \mathrm{kg})$, butorphanol $(0.02 \mathrm{mg} / \mathrm{kg})$, guaifenesin $5 \%(20 \mathrm{mg} / \mathrm{kg})$, and ketamine $(2.2 \mathrm{mg} / \mathrm{kg})$ combination can safely be used for total intravenous anaesthesia for short-term procedures in equines under field conditions where the monitoring facilities are meager. The combination produces minimal side effects without any hepatic or renal toxicity.

\section{References}

[1] L. W. Hall and K. W. Clarke, "Anaesthesia of the horse," in Veterinary Anaesthesia, L. W. Hall and K. W. Clarke, Eds., pp. 191-235, Bailliere Tindall, London, UK, 9th edition, 1991.

[2] A. A. Garcia, H. Sumano, and E. Nunez, "Pharmacological basis of short term intravenous general anaesthesia in the equines," Veterinaria México, vol. 33, no. 3, pp. 309-333, 2002.

[3] V. S. Nanda, Clinical evaluation of continuous maintenance anaesthesia using guaifenesin or diazepam combined with xylazine and ketamine in equines, M.S. thesis, Department of Veterinary Surgery and Radiology, CSK Himachal Pradesh Krishi Vishvavidyalaya, Palampur, India, 2009.

[4] S. K. Ringer, K. Kalchofner, J. Boller, A. Fürst, and R. Bettschart-Wolfensberger, "A clinical comparison of two anaesthetic protocols using lidocaine or medetomidine in horses," Veterinary Anaesthesia and Analgesia, vol. 34, no. 4, pp. 257-268, 2007.

[5] C. L. Kerr, W. N. McDonell, and S. S. Young, "A comparison of romifidine and xylazine when used with diazepam/ketamine for short duration anesthesia in the horse," Canadian Veterinary Journal, vol. 37, no. 10, pp. 601-609, 1996.

[6] W. W. Muir, R. T. Skarda, and D. W. Milne, "Evaluation of Xylazine and ketamine hydrochloride for anesthesia in horses," American Journal of Veterinary Research, vol. 38, no. 2, pp. 195-201, 1977.

[7] T. S. Butera, J. N. Moore, H. E. Garner, J. F. Amend, L. L. Clarke, and D. G. Hatfield, "Diazepam/xylazine/ketamine combination for short-term anesthesia in the horse," Veterinary Medicine Small Animal Clinician, vol. 73, no. 4, pp. 490499, 1978.

[8] J. S. Kaka, P. A. Klavano, and W. L. Hayton, "Pharmacokinetics of ketamine in the horse," American Journal of Veterinary Research, vol. 40, no. 7, pp. 978-981, 1979.

[9] W. W. Muir, R. T. Skarda, and W. Sheehan, "Evaluation of xylazine guaifenesin, and ketamine hydrochloride for restraint in horses," American Journal of Veterinary Research, vol. 39, no. 8, pp. 1274-1278, 1978.

[10] J. A. Hubbell, K. W. Hinchcliff, L. M. Schmall, W. W. Muir III, J. T. Robertson, and R. A. Sams, "Cardio respiratory and metabolic effects of xylazine, detomidine and a combination of xylazine and acepromazine administered after exercise in horses," American Journal of Veterinary Research, vol. 60, no. 10, pp. 1271-1279, 1999.

[11] W. H. Hsu, "Xylazine-induced depression and its antagonism by alpha adrenergic blocking agents," Journal of Pharmacology and Experimental Therapeutics, vol. 218, no. 1, pp. 188-192, 1981.

[12] J. E. McCarty, C. M. Trim, and D. Ferguson, "Prolongation of anesthesia with xylazine, ketamine and guaifenesin in horses: 64 cases (1986-1989)," Journal of the American Veterinary Medical Association, vol. 197, no. 12, pp. 1646-1652, 1990.

[13] C. L. Baetge, N. S. Matthews, and G. L. Carroll, "Comparison of 3 total intravenous anaesthetic infusion combinations in adult horses," International Journal of Applied Research in Veterinary Medicine, vol. 5, no. 1, pp. 1-8, 2007.

[14] F. Staffieri and B. Driessen, "Field anesthesia in the equine," Clinical Techniques in Equine Practice, vol. 6, no. 2, pp. 111119, 2007.

[15] M. L. Aubin and K. Mama, "Field anesthetic techniques for use in horses," Compendium on Continuing Education for the Practicing Veterinarian, vol. 24, no. 5, pp. 411-417, 2002.

[16] J. Bertone and L. J. I. Horspool, "Anaesthetics, tranquillizers and opioid analgesics," in Equine Clinical Pharmacology, J. Bertone and L. J. I. Horspool, Eds., pp. 267-310, Saunders, Elsevier, 1st edition, 2004.

[17] D. L. Sparks, G. Corssen, J. Sides, J. Black, and A. Kholeif, "Ketamine-induced anesthesia: neural mechanisms in the Rhesus monkey," Anesthesia and Analgesia, vol. 52, no. 2, pp. 288-297, 1973.

[18] M. Wright, "Pharmacologic effects of ketamine and its use in veterinary medicine," Journal of the American Veterinary Medical Association, vol. 180, no. 12, pp. 1462-1471, 1982.

[19] L. K. Cullen, "Muscle relaxants and neuromuscular block," in Lumb and Jones Veterinary Anaesthesia, J. C. Thurmon, W. J. Tranquilli, and G. J. Benson, Eds., pp. 358-359, Williams and Wilkins, Baltimore, Md, USA, 3rd edition, 1996.

[20] D. R. Geiser and J. E. Henton, "Xylazine and butorphanol: survey of field use in the horses," 2006, http://www.cabi.org/.

[21] R. C. Purohit, P. W. Mysinger, and R. W. Redding, "Effects of xylazine and ketamine hydrochloride on the electroencephalogram and the electrocardiogram in the horse," American Journal of Veterinary Research, vol. 42, no. 4, pp. 615-619, 1981.

[22] D. M. Rings and W. W. Muir, "Cardiopulmonary effects of intramuscular xylazine-ketamine in calves," Canadian Journal of Comparative Medicine, vol. 46, no. 4, pp. 386-389, 1982.

[23] J. T. Robertson, W. W. Muir, and R. Sams, "Cardiopulmonary effects of butorphanol tartrate in horses," American Journal of Veterinary Research, vol. 42, no. 1, pp. 41-44, 1981.

[24] J. A. E. Hubbel, “Options for field anaesthesia in horse," in Proceedings of the 45th AAEP Annual Convention, vol. 45, pp. 120-121, Albuquerque, NM, USA, December 1999.

[25] S. K. Tiwari, A. Kumar, and P. V. Parikh, "Clinico-surgical effects of epidural xylazine and detomidine with or without local anaesthesia in buffaloes," Indian Journal of Veterinary Surgery, vol. 76, no. 2, pp. 108-111, 1999.

[26] I. Angel and S. Z. Langer, "Adrenergic-induced hyperglycemia in anaesthetized rats: involvement of peripheral $\alpha 2-$ adrenoceptors," European Journal of Pharmacology, vol. 154, no. 2, pp. 191-196, 1988. 
[27] L. E. Young, D. H. Bartram, M. J. Diamond, A. S. Gregg, and R. S. Jones, "Clinical evaluation of an infusion of xylazine, guaifenesin and ketamine for maintenance of anaesthesia in horses," Equine Veterinary Journal, vol. 25, no. 2, pp. 115-119, 1993.

[28] M. Singh, V. Kumar, A. C. Varshney, S. K. Sharma, and J. M. Nigam, "Clinico-biochemical effect of xylazine administration in spiti ponies," Centaur, vol. 13, no. 2, pp. 21-23, 1996. 

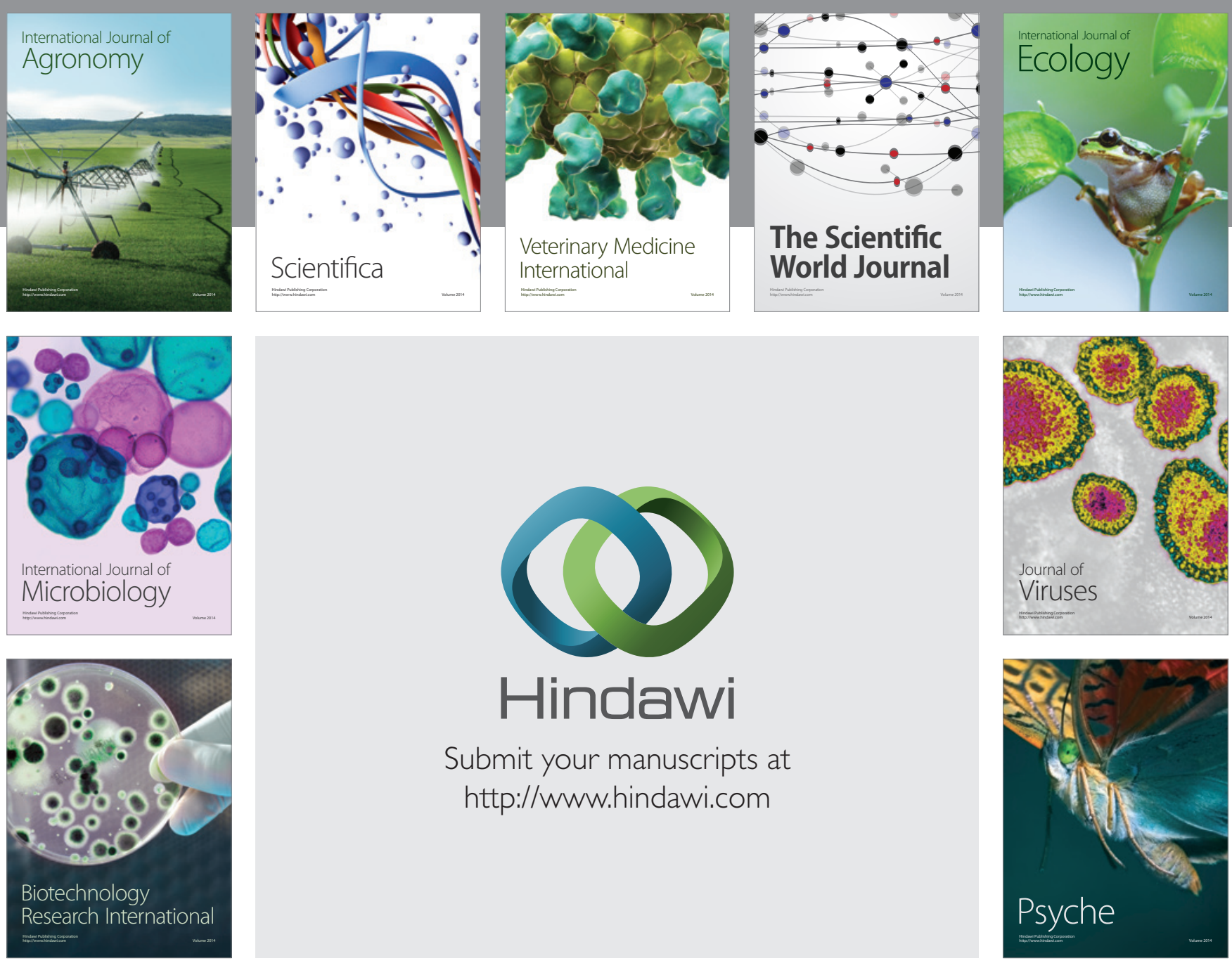

Submit your manuscripts at

http://www.hindawi.com
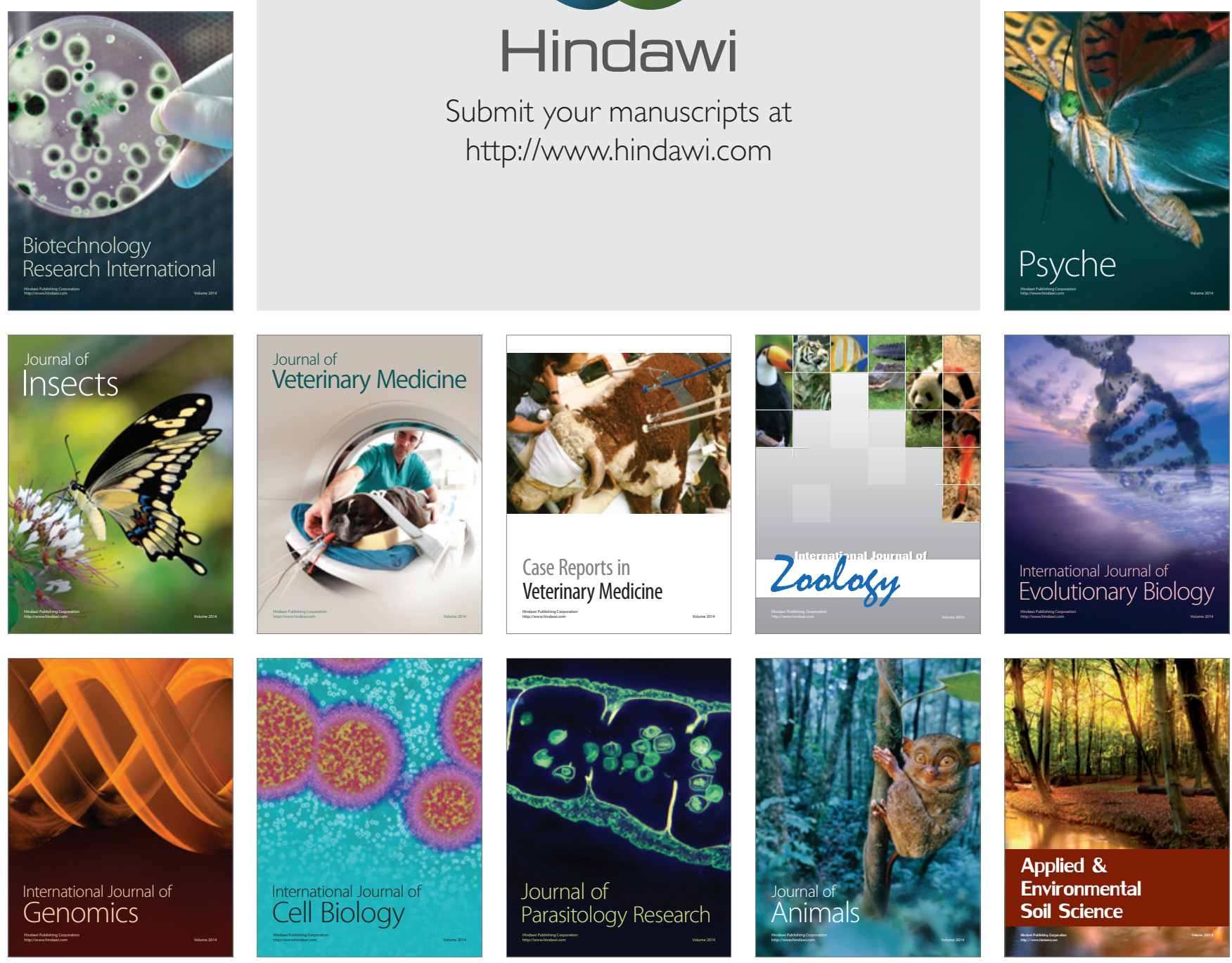